\title{
O que Deus e uma noção de saúde tem a ver com conflitos socioambientais no Brasil'
}

\author{
What God and a notion of health have to do with the socio-environmental \\ conflicts in Brazil
}

Edvan Lessa dos Santos '; Antonio Carlos Rodrigues de Amorim "

\section{RESUMO}

A Comissão Pastoral da Terra (CPT) assina um denso trabalho sobre conflitos socioambientais no país, o Conflitos no Campo Brasil, que desvela mobilizações de sujeitos ante atos iminentes ou deflagrados contra seus modos de vida. As informações denunciam e anteveem o cenário conflitivo do país, devido à recorrência com que os dados vêm à tona. O Mapa de Conflitos envolvendo Injustiça Ambiental e Saúde no Brasil, por sua vez, desoculta e denuncia, num site, conflitos nacionais e tem autoria da Fundação Oswaldo Cruz (Fiocruz). Analisamos o Mapa -site e livro sobre a ferramenta - e 14 edições do Conflitos no Campo Brasil. Neste artigo, destacamos aspectos distintivos e comuns de ambos, salientando as correlações com religião feitas pela CPT ao divulgar os conflitos e, no caso da Fiocruz, por que tais lutas envolvem uma compreensão abrangente de saúde.

Palavras-chave: Fiocruz; CPT; Conflitos Socioambientais.

\footnotetext{
${ }^{1}$ Artigo baseado na dissertação de Mestrado Água mole, terra dura, povo brada até que fura : o que narram CPT e Fiocruz sobre os conflitos socioambientais no Brasil, defendida no Labjor/ Unicamp. Financiamento: CNPq.
}

\footnotetext{
' Universidade Estadual de Campinas, Campinas, Brazil. lessaedvan@gmail.com

"Universidade Estadual de Campinas, Campinas, Brazil. acamorim@unicamp.br
} 


\section{ABSTRACT}

The Pastoral Land Commission (CPT) signs a dense work about socio-environmental conflicts in the country, the Conflict in the Field Brazil, which unveils mobilizations of subjects before imminent or deflagrated actions against their ways of lives. The information denounces and foresees the conflictive scenario of the country, due to the recurrence of the data. The Map of Conflicts involving Environmental Injustice and the Health in Brazil denounces, on a website, national conflicts and is authored by the Oswaldo Cruz Foundation (Fiocruz). We analyzed the Map - site and book about the tool - and 14 editions of Conflicts in the Field Brazil. In this article, we highlight distinctive and common aspects of both and the correlations with religion made by the CPT in publicizing the conflicts and, in the case of Fiocruz, why such struggles involve a comprehensive understanding of health.

Keywords: Fiocruz; CPT; Socio-Environmental Conflicts.

\section{INTRODUÇÃO}

O planeta, conforme enuncia a fé a cristã, com as formas de vida existentes e o meio ambiente, é criação de Deus. “O que vem ocorrendo é que as obras das mãos de Deus estão sendo violentadas por mãos humanas. Portanto, é um assunto a ser pautado pela teologia e de forma profética" (PEREIRA PI, 2012, p. 43).

O pressuposto em questão alude ao argumento no qual se embasa a CPT na documentação dos conflitos socioambientais brasileiros sob um argumento teológico, isto é, de que para documenta-los existe uma justificativa/razão ou ideal biblicamente sustentado. Mas outros autores nos ajudam a avançar nesta afirmação, incluindo o que esboça a própria CPT, conforme observaremos adiante.

Para Leonardo Boff, tanto ecologia, cultura, sociedade e política quanto espiritualidade são respostas para os conflitos humanos, em um momento em que as dificuldades da humanidade adquirem novas proporções (DIAS, 2010, p. 201). $\mathrm{Na}$ 
discussão sobre conflitos socioambientais, os trabalhos elaborados pela Fiocruz e CPT nos direcionam, respectivamente, para um olhar sobre um desfecho em saúde e uma dimensão teológica para compreender as suas motivações.

Na concepção dos cadernos Conflitos no Campo, da CPT, Deus não é responsável pelo sofrimento e miséria em nosso país, "como se dá a entender quando se diz que 'as coisas estão assim porque Deus quer'. Não é vontade de Deus que o povo sofra e viva na miséria" (CNBB, 1980, p.4). Ao oferecer o contexto religioso para possíveis causas dos conflitos (fatores prosaicos), não se buscaria uma dimensão religiosa para justificar os conflitos, mas para apoiar o argumento de que, biblicamente, eles promovem distorções.

Ligada à igreja católica - daí a plausibilidade dessa inclinação religiosa -, a CPT busca por correlacionar o direito à vida pacífica e aos recursos ambientais com princípios bíblicos/religiosos. Justifica-se, pois, o fato de que "a religião e toda sua dinamicidade estão envoltas em questões que ultrapassam os ditames espaciais - no sentido de materialidade exterior" (PEREIRA CLE, 2013, p. 32).

A Fiocruz, por sua vez, estabelece uma noção ampliada de saúde, isto é, uma determinação socioambiental que se distancia da perspectiva biomédica e epidemiológica. Nesse sentido, recorremos a autores da saúde coletiva para considerarmos como as disputas sociais se vinculam com o debate ligado à saúde muito embora estejamos preocupados em discutir como a saúde aparece como um tema ligado aos conflitos socioambientais em especial e como a Fiocruz denota isso em seu Mapa de Conflitos.

Historicamente, destaque-se, as sociedades identificam os seus problemas de saúde; buscam a sua explicação e se organizam para enfrentá-los de maneiras distintas, dependendo, para isso, considerar determinantes estruturais econômicos, políticos e ideológicos associados a estas demandas (PAIM, 2006, p. 117). Assim, cabe não só observar que há uma contribuição da teologia e da espiritualidade no enfretamento dos problemas que impactam na saúde, como também entender que 
essa implicação na saúde passa por entendermos antes que o referido campo não se organiza somente numa dimensão biomédica.

Esse estudo se organiza sob métodos qualitativos de sistematização de informações publicadas em formato digital e impresso. Através da análise qualitativa de mapas, tabelas, fotografias e textos, contidos em 15 livros (14 da CPT e um da Fiocruz); dezenas de páginas impressas e online, extraímos excertos dos textos, num esforço de detectar como se a Fiocruz e CPT constituiriam uma narrativa que divulga os conflitos no Brasil e como isso se vincula à religião e saúde na prática.

Há quatro décadas, ressalte-se, o olhar que a CPT lança sobre a situação dos povos do campo sugere que a pauta dos conflitos socioambientais é uma constante na agenda nacional, embora não seja satisfatoriamente agendada na esfera pública, por exemplo, pela imprensa. Ainda hoje, diversos conflitos permanecem ocultados ou são sub detectados.

No caso da Fiocruz, ao manter atualizado o seu mapa online, a instituição sugere que ao longo dos anos muitas situações permanecem sem resolução. Assim, enquanto a Fiocruz se orienta por um discurso baseado na ciência; saúde coletiva e na política ao informar os conflitos por meio do Mapa de Conflitos, a CPT mescla seus argumentos, também sob a dimensão científica e política, enfatizando a religião.

A contribuição deste trabalho, dentro das suas limitações, envolve pensar em como o debate sobre conflitos socioambientais no Brasil passa, na contemporaneidade, por pensar uma dimensão teológica do problema e um desfecho que tem a ver com a saúde das pessoas envolvidas, especialmente povos e comunidades tradicionais. As aproximações entre Mapa de Conflitos e caderno de Conflitos, aqui observadas, são fruto de uma análise de conteúdo, em separado, das publicações em questão e não se apoiam essencialmente em opiniões de seus autores, por exemplo. 


\section{CAMINHOS DE ANÁLISE}

Numa abordagem qualitativa, analisamos dois conjuntos de publicações impressas e digitais. No caso das edições do Caderno de Conflitos, estudamos os arquivos publicados entre 2003 e 2016 (edições numeradas de 2002 a 2015). A escolha do ano inicial se deu pelo fato deste ser o momento em que a Pastoral da Terra iniciava um trabalho consistente de registro, divulgação e denúncia de conflitos pela água Brasil afora. No ano de 2016, por sua vez, foi lançado um texto (Conflitos no Campo Brasil 2015), que demarcava uma parceria entre CPT e Fiocruz.

Após analisar sistematicamente textos diversos contidos nos cadernos, organizamos as informações em tabelas nas quais elencamos categorias de análise que evidenciariam a ocorrência de uma narrativa sobre os conflitos socioambientais pautada num discurso de religião e saúde. A ocorrência dessa narrativa foi objeto de outras publicações dos autores.

O caráter exploratório da pesquisa adquiriu argumentos sólidos na interlocução com teóricos das ciências sociais, geografia, como também a partir das próprias reflexões contidas em excertos retirados das publicações analisadas. No caso do Mapa de Conflitos envolvendo Injustiça Ambiental e Saúde, da Fiocruz, seguimos a mesma lógica analítica a partir da única publicação disponível sobre o tema: o livro de nome homônimo, e dos textos contidos na plataforma online ${ }^{2}$.

Tensionando as assimetrias de saberes em que muitas vezes são colocadas análises textuais, operamos com autores alheios às publicações e fragmentos dos referidos materiais analisados. Isso porque entendemos que eles nos servem para explicitar o que argumentamos. Além disso, uma vez que não pretendemos superálos do ponto de vista de uma crítica, e são cientificamente elaborados, nos servem

\footnotetext{
${ }^{2}$ Disponível por meio do domínio digital do ICICT/Fiocruz, o Mapa da Fiocruz exibe dados cartográficos utilizando o Google Earth. Na parte superior do site há caixas de busca com as opções "palavra-chave", "UF", "tipo de população" e "causa do conflito". As informações são oriundas de "parcela expressiva das populações atingidas, seja a partir de suas experiências, seja a partir de relatórios e artigos desenvolvidos por entidades, ONGs e instituições parceiras, inclusive grupos acadêmicos, instituições governamentais, Ministérios Públicos ou órgãos do judiciário" (Fiocruz, 2016). Os casos relatados, todavia, não são categóricos, podendo haver incertezas e falta de informações. O site está disponível no endereço: http://mapadeconflitos.ensp.fiocruz.br/.
} 
também para refletir de uma maneira metalinguística, em pensamentos teóricos de suas próprias bases.

\section{BREVES DEFINIÇÕES SOBRE “CONFLITOS”}

Conflito é um termo flutuante e que depende de complementos explicativos, ou seja, contexto, personagens, antecedentes e ambientação. O conflito na sociedade pode extrapolar fronteiras regionais ou se restringir a pequenos territórios - muitas vezes distantes de grandes centros urbanos. Apesar disso, são plausíveis de denúncia, conforme impactam negativamente modos de vida e não apresentam soluções tácitas.

Conforme salienta Galtung (1996), cada conflito pressupõe uma contradição, algo que está no caminho de algo mais; entendido, pois, como um problema. E é justamente um problema a ser resolvido que, segundo o autor, poderia servir como força motriz para atores individuais ou coletivos (GALTUNG, 1996, p. 70). Outros teóricos discordam especialmente da ideia de "problema" vinculada a esta afirmação.

Baseando-se no debate das ciências sociais, Ferreira (2012) afirma que os conflitos sociais e recursos naturais estariam entre os dilemas intelectuais impostos pela realidade social nos últimos anos do século XX e início do XXI, o que, portanto, justificaria a sua existência como tema significativo de estudo.

Conforme propõe a CPT, por definição, conflitos são "as ações de resistência e enfrentamento que acontecem em diferentes contextos sociais no âmbito rural, envolvendo a luta pela terra, água, direitos e pelos meios de trabalho ou produção. Estes conflitos acontecem entre classes sociais, entre os trabalhadores ou por causa da ausência ou má gestão de políticas públicas" (CPT, 2016).

Apoiados em Fiocruz e Zhouri (2013), entendemos que os conflitos evocam noções de justiça, democracia e também participação. Daí, que ocorrem não em busca de conformações, mas pela legitimidade de outras formas possíveis de divisão 
do ambiente e do espaço social. Porém, presumir lugares intrínsecos a determinados sujeitos é reconhecer modos tradicionais e originários de viver, e não um status quo impossível de ser constrangido - até porque isso seria impossível.

Com base em Funtowicz \& Ravetz (1994), citado em Dias (2013), conflitos, além de valores e incertezas, caracterizam os problemas socioambientais mais graves e urgentes da nossa época. A incerteza costuma ser marca dessas situações, até porque as mobilizações ocorrem por "trocas de calor", sem um termômetro que meça a sua variação.

\section{A CPT, O CADERNO DE CONFLITOS E UMA NOÇÃO DE RELIGIÃO}

A atuação da $\mathrm{CPT}^{3}$, por meio dos cadernos Conflitos no Campo, vai na contramão da crítica que o autor Leonardo Boff faz à mensagem cristã pela corresponsabilidade da crise ecológica na qual o mundo se encontra. De acordo com o autor, a interpretação do livro de Gêneses, na Bíblia, legitimou posturas destruidoras e colocou o homem como dominador da criação, o que deixou a terra entregue a agressões humanas; a reflexão cristã se espiritualizou e não deu atenção ao mistério da criação (DIAS, 2010, p. 200).

Ao mesmo tempo, Boff compreende que a igreja e a espiritualidade têm papel importante na manutenção da esperança (p. 201). Admite-se, pois, que "o impacto da religião nas questões ambientais não pode ser reduzido a esse modelo judaico-cristão dicotômico ou simplista" (HAYES \& MARANGUDAKIS, 2000, p.171). Com isso, depreende-se do ponto de vista epistemológico como a religião cumpriria um dever social de reparar as distorções que teriam levado a uma subjugação biblicamente respaldada do meio ambiente - e que são hoje razão para conflitos entre projetos de desenvolvimento e povos com modos de vida autóctones.

\footnotetext{
${ }^{3}$ A CPT é uma ação pastoral da igreja católica vinculada à Comissão para o Serviço da Caridade da Justiça e a Paz da CNBB. Esse organismo é membro da Pax Christi Internacional, um movimento católico que prega a paz e aborda causas e consequências destrutivas de conflito e guerra.
} 
Ainda oferecendo um contexto, considere-se que o nascimento da pastoral se deu durante a ditadura militar, em resposta à grave situação dos trabalhadores rurais, posseiros e peões na Amazônia. "Ela nasceu ligada à Igreja Católica porque a repressão estava atingindo muitos agentes pastorais e lideranças populares, e também, porque a igreja possuía uma certa influência política e cultural". (CPT, 2016). A confluência entre a agenda ambiental e religiosa surgiu, pois, por consequência de um movimento em defesa de direitos sociais e ambientais, num momento em que as violências promovidas pelo Estado eram constantes.

A Pastoral da Terra age em prol dos trabalhadores e trabalhadoras da terra com base no Evangelho. "Por fidelidade 'ao Deus dos pobres, à terra de Deus e aos pobres da terra"' (CPT, 2004, p.216). "Os profetas bíblicos emergem em momentos de crise do povo. Aí tomam como referência valores e padrões de comportamento tradicionais, considerados bons e sancionados por Deus." (REIMER, 1992, p. 229).

A Pastoral da Terra registra e também denuncia os conflitos e a violência no campo, incluindo a violação dos direitos dos camponeses. "a CPT, leal à sua missão de serviço aos pobres da terra e das águas, ergue a sua voz profética frente aos senhores da guerra e brada a toda sociedade" (CPT, 2004, p. 202).

A questão fundiária era um assunto proibido durante os governos miliares e passou a fazer parte do debate nacional em 1985 com a criação do Ministério da Reforma e do Desenvolvimento Agrário (Mirad). Todavia, cinco anos antes um documento da Conferência Nacional dos Bispos do Brasil (CNBB), intitulado "A igreja e os problemas da terra", denunciava com veemência a "extrema violência da luta pela terra em nosso país, com características de uma guerra de extermínio, em que as baixas mais pesadas estavam do lado dos lavradores pobres" (CNBB, 1980, p. 4).

O entendimento, ainda conforme a CNBB, é de que as injustiças que recaem sobre os povos do campo e comunidades tradicionais concretizam ou localizam a "injustiça institucionalizada" presente da na zona rural. A contribuição das igrejas 
remete à capacidade de luta por terra e pelos direitos dos trabalhadores que a ditadura militar reprimia.

As igrejas tentavam compreender o que acontecia e se posicionar. Foi a partir do trabalho desempenhado pelas igrejas que os conflitos passaram, inclusive, a serem conhecidos publicamente e a CPT contribuiu para a visibilidade política dessas situações e também das violências. Chegou-se ao ponto de dizer que a pastoral "criava os conflitos pela terra" (BOECKER, 2004, p. 14).

Os autores Hayes \& Marangudakis (2000) afirmam que a relação entre identificação religiosa e questões ambientais é complexa e variável. O significado dessa relação é altamente dependente de como a identificação religiosa é definida, e de qual aspecto do ambientalismo é considerado (p. 171).

Em sua obra "Ecologia, Mundialização e Espiritualidade", Leonardo Boff, ao apresentar a espiritualidade e a mística, aponta que a disposição para um cuidado integrador - isto é, não apenas restrito à proteção ambiental - se manifesta na sensibilidade, no encontro fraterno entre seres humanos e com a natureza (DIAS, 2010, p. 200). Nesse sentido, os Cadernos de Conflitos da CPT narrariam formas dessa coexistência, na medida em que desvelam os graves e repetidos conflitos a partir de distintas demandas socioambientais.

A perspectiva traduzida nos Cadernos de Conflito apontam para uma noção mais ampliada de ambiente, em que povos e comunidades; terras e águas são interdependentes. Com efeito, a "crise ecológica ganha (...) um sentido interpelador. É Deus que questiona o processo de administração destrutiva da casa comum de sua criação" (REIMER, 1992, p. 226).

Enquanto ação pastoral, a CPT tem sua raiz e fonte no Evangelho. Ainda assim, são aplicados procedimentos e metodologias das ciências, conceitos e temáticas que envolvem as equipes de documentação e os agentes de base da CPT, bem como movimentos sociais que atuam no espaço rural. 
Um tanto da narrativa expressa nos Cadernos da CPT se apoia em saberes canônicos. O discurso baseado em religião está bastante presente, pois as motivações intrínsecas à publicação remetem ao "duplo signo da paixão e da esperança. Paixão no sentido bíblico-litúrgico e esperança conforme o imaginário do nosso povo" (BALDUINO, 2003, p.7). Por isso, enquanto a ciência tenta responder, "invoca-se a força do Deus da Vida plena e da Terra nova" (p.7). Numa visão dicotômica, a religião - que coloca o tema em suspenso - questionaria, enquanto a ciência viria a responder tais questões.

A CPT considera e distingue, na verdade, seis dimensões nas suas publicações, dentre elas a dimensão teológica, "de acordo com a tradição bíblica”. “Deus ouve o clamor do seu povo e está presente na luta dos trabalhadores e trabalhadoras (Ex 3, 7-10). Esta luta é em si mesma um ritual celebrativo desta presença e da esperança que anima o povo" (CPT, 2012, p. 9). O trecho traz consigo elementos que descortinam, nas próprias palavras da CPT, o contexto religioso no qual emerge a documentação dos conflitos socioambientais.

Conforme excertos da publicação, a divindade é "invocada" a estar com o povo do campo e com aqueles que estão ao seu serviço, isto é, os assessores da pastoral que atual junto aos movimentos sociais e povos rurais. Ainda segundo a entidade, sem esses agentes em campo os dados não estariam publicados.

De acordo com Galazzi (2014), são eles que sentem na pele o sofrimento das pessoas e transformam em números o grito de dor, muitas vezes abafado, que se ergue do chão, da terra, das florestas e das águas. Ainda em referência a esses agentes, o autor aponta que, além do sofrimento escondido nos números, há "a compaixão, indignação e raiva em nosso coração de 'pastores e pastoras da terra' [...], movidos e movidas pela fidelidade ao Deus dos pobres e na certeza que a terra de Deus é para a vida de todos e de todas" (GALLAZZI, 2014, p. 63 e 64).

O caráter religioso do debate sobre os conflitos socioambientais na perspectiva dos cadernos Conflitos no Campo Brasil traduz, ainda conforme denotam excertos da 
publicação, a missão testemunhal e profética a serviço dos pobres da terra. Uma vez que apropriou da árvore da vida, a "sociedade humana conseguiu pôr em desequilíbrio a Criação. A terra é só uma e os recursos são finitos" (CORTES, 2011. p. 88).

Referências bíblicas ajudam a compreender a dimensão profética - e vivencial do Caderno da Pastoral e que "nem o registro do jornalista, nem a análise do pesquisador" (CORTES, 2011. p. 88) conseguiriam. Com isso, equilibram-se saberes e minimizam-se possíveis assimetrias do ponto de vista dos tipos de conhecimento circundantes na atuação da entidade, refletidos na publicação anual.

A perspectiva bíblica para o que se entende por Justiça move a narrativa do Caderno de Conflitos, isto é, o ideal de uma justiça divina. Há uma crítica declarada também às igrejas cristãs que apoiam políticos. "Querem apagar as luzes das religiões de outras matrizes, altares de terreiros e rituais de torés. Faz escuro e silêncio na longa noite da religião do patriarcalismo, individualismo e consumismo" (CPT, 2016, p. 192). Nesse ponto, evoca-se a dimensão mundana para situar o ideal divino do qual ela destoa.

Com efeito, as considerações religiosas nos cadernos Conflitos no Campo Brasil analisados fazem emergir a fala de autores que se veem como "iguais" aos atingidos por conflitos. "Cristo vivo ressuscitado na humana solidariedade e no amor pelo mundo e seus viventes" (CPT, 2016, p.192). Até porque, segundo a bíblia, há um desejo de "levar fogo sobre a terra que já deveria estar em chamas" (p.192). O discurso teológico de justiça assume, portanto, oscila entre a motivação cristã para a defesa dos direitos daqueles subjugados nos conflitos como também conclama uma justiça que, do ponto de vista de um "Deus justo", pesaria a mão sobre os homens não cristãos.

\section{A FIOCRUZ, O MAPA DE CONFLITOS E UMA DISCUSSÃO SOBRE SAÚDE}

A Fiocruz é uma das mais destacadas instituições de ciência e tecnologia em saúde da América Latina, sobretudo, por seu relevante desempenho na pesquisa e ensino; na produção e inovação; nos serviços de saúde, bem como na comunicação e 
informação em saúde. O Mapa de Conflitos é produzido por uma equipe da Escola Nacional de Saúde Pública Sergio Arouca (ENSP), coordenada por Marcelo Firpo e Tania Pacheco, e uma equipe diversa de profissionais. O website onde está publicado o mapa foi feito por uma equipe do Instituto de Comunicação e Informação Científica e Tecnológica em Saúde (ICICT), também ligado à Fiocruz.

O Mapa tem a sua importância destacada por ser, segundo a Fiocruz (2013), um tipo de monitor dedicado à interface entre saúde e ambiente que disponibiliza informações estratégicas sobre o tema à toda população. A sua montagem começou a ser feita em 2008 - sob responsabilidade da Fiocruz e Fase, a partir de cooperação iniciada em 2004 - e apoio do Departamento de Vigilância em Saúde Ambiental e Saúde do Trabalhador, do Ministério da Saúde.

Lançado oficialmente em 2010 com 297 conflitos em todos os estados, salvo o DF, o Mapa identifica, sistematiza e torna públicos os conflitos provenientes das lutas contra as injustiças ambientais em locais onde estão ou serão realizados projetos econômicos e políticas governamentais. Do ponto de vista prático, ao acessar o website, filtra-se por estado federativo o número de conflitos e, a partir deste acesso, fichas específicas que apontam para o contexto, descrição e impacto dos conflitos na saúde dos envolvidos.

De acordo com Paim (2006), quando se considera a ação política (estratégica e comunicativa) como pertinente para intervir no coletivo, a Saúde Pública/Coletiva necessita manter o diálogo e a crítica teórica aos movimentos ideológicos antigos e novos (PAIM, 2006, p. 134). Nesse ponto, depreende-se um dos argumentos sob os quais os conflitos socioambientais são pensados também numa perspectiva que envolve saúde.

Segundo Faustino et al. (2013), "o mapa convoca a sociedade a tomar ciência e reavaliar sua visão sobre conflitos socioambientais e sobre as lutas sociais e seus sujeitos mobilizadores nele refletidos [...] (FAUSTINO et al., 2013, p.257). A autora também afirma que o exercício soberano da cidadania ocorre quando se é capaz de 
interferir no debate público e nas práticas relacionadas ao modelo dominante de desenvolvimento. Considerar os determinantes sociais da saúde, e não apenas uma dimensão biomédica possibilita admitir que os conflitos trazem riscos aos sujeitos vulnerabilizados em seus territórios.

A Conferência das Nações Unidas sobre Meio Ambiente e Desenvolvimento, realizada em 1992, na cidade do Rio de Janeiro, resultou na Agenda 21, um programa de ações para o século XXI, considerado notável na pauta ambiental. No capítulo 6 do referido trabalho, há uma seção que reconhece a saúde ambiental como prioridade social para a promoção da saúde (FREITAS, 2005, p. 679-680). O debate que conecta saúde e demandas ambientais não se restringe à dimensão dos conflitos, mas por ele passa de maneira sistematicamente apresentada no Mapa de Conflitos.

Para a Fiocruz (2013), a ideia de "saúde" no contexto dos conflitos tem origem na constatação da não respeitabilidade do princípio da precaução. Este conceito versa que a proteção da vida está acima de quaisquer atividades humanas que possam pôlas em perigos moralmente inaceitáveis plausíveis para a ciência e que apresentem incertezas socioambientais.

Segundo Leroy (2013), tal compreensão não reflete somente a dimensão biomédica dos impactos ao meio ambiente, como também qualidade de vida, cultura e tradições, direitos humanos e capacidade de organizações e mobilizações coletivas. Além de problemas de saúde clássicos, há várias formas de violência que conectam a saúde ao campo dos direitos humanos e da democracia (LEROY, 2013, p. 65).

Outras questões consideradas básicas de saúde, conforme esboçam as fichas disponíveis no website do Mapa de Conflitos se referem: a) ao problema de insegurança alimentar; b) das doenças não transmissíveis (como o câncer e as doenças respiratórias decorrentes da poluição química); c) os acidentes; d) a falta de assistência médica adequada e de estudos que associem tais problemas de saúde com os problemas ambientais na região; e) o agravamento das doenças transmissíveis pela degradação ambiental e falta de saneamento básico. Além disso, a 
violência aprece como problema de saúde - traduzida em coações, ameaças e assassinatos.

Conforme também está destacado no site do Mapa de Conflitos, a concepção de saúde é ampliada porque diz respeito, dentre outras coisas, à qualidade de vida, à cultura e tradições, aos direitos humanos e à capacidade de organização e mobilização coletivas. A Fiocruz entende que, por meio do Mapa, está contribuindo para a construção de ambientes mais saudáveis; uma sociedade mais fraterna, igualitária em que a dignidade humana não seja violada (o que é biblicamente sustentado pela CPT).

Diferentemente do que se poderia fazer supor, não está em jogo somente evitar prejuízos decorrentes de impactos ambientais, mas manter práticas sociais consideradas autóctones; valores e relações com a natureza para que não despareçam. Nesse sentido, a noção de qualidade vida, de acordo com a Fiocruz, merece destaque: "representa uma visão complexa que rejeita a ideia de crescimento, riqueza e consumismo à custa da perda dos próprios valores e sentidos de vida comunitária" (FIOCRUZ, 2018).

\section{LINHAS FINAIS}

Nas primeiras análises do corpus de pesquisa (Mapa de Conflitos e cadernos Conflitos no Campo Brasil), percebemos que, no livro impresso em que discorre acerca do seu mapeamento, a Fiocruz faz referências às "organizações ligadas às igrejas", mas não especifica o trabalho da CPT. Porém, uma efetiva parceria entre as duas instituições ocorreu na publicação lançada em 2016 pela CPT, em que há um texto dos autores do Mapa.

Para entender como ela opera no âmbito de levantamento de conflitos, é necessário também desconstruir entendimentos naturalizados sobre a noção de saúde. Neste artigo destacamos definições de saúde ou termos que traduziriam esta 
compreensão específica em que se orienta o Mapa da Fiocruz Ao mesmo tempo, salientamos alguns trechos em que a menção à religião aparece ao longo dos livros (também chamados de cadernos) analisados.

A existência do Mapa e Cadernos remetem a acordos institucionalizados em que se inserem, em seus respectivos contextos, Fiocruz e Pastoral. Se a Conferência da CNBB foi determinante para o serviço prestado pela CPT, o que baliza a atuação da Fiocruz, ao vincular saúde e ambiente, é o debate circundante no campo da Saúde Pública/Coletiva com raiz na Conferência das Nações Unidas sobre Meio Ambiente e Desenvolvimento.

Conforme apontado por autores supracitados, a perspectiva teológica em alguma medida já foi acusada de contribuir com a crise ambiental em que se inserem os conflitos. Ao mesmo tempo, o papel desempenhado pela CPT na publicação dos cadernos endossa a tese de que cabe à espiritualidade atuar nas tensões sociais, ou seja, os conflitos humanos, como um forma de reparar um erro histórico.

O paradigma biomédico, por sua vez, se revela limitado face aos antagonismos sociais e, por isso, evoca-se a saúde coletiva. Da mesma forma como a dimensão religiosa não parece ser suficiente para desvelar os conflitos - o que justifica o fato da CPT dialogar com outros campos -, para a Fiocruz, romper a dimensão biomédica se constitui como uma forma de assegurar mais justiça nesse esforço de não apenas documentar, como também de denunciar os conflitos, trazendo-os a público.

Por outro lado, a edição Conflitos no Campo Brasil 2015 inaugurou uma parceria entre ambas as instituições e expôs a aproximação entre a CPT e a Fiocruz. O texto intitulado "Agrotóxicos, armas de uma guerra não declarada", assinado pelos três autores que organizaram o Mapa de Conflitos Envolvendo Injustiça Ambiental e Saúde, marcou essa conexão entre ambos os trabalhos.

Não há, apesar disso, relação simétrica entre os trechos que sugerem a ocorrência de uma narrativa única sobre os conflitos brasileiros, a partir dos Cadernos e Mapa de Conflitos. A forma como a CPT aponta para a dimensão religiosa 
não é apenas contundente, mas traço distintivo da realidade que constrói, enquanto que a relação entre conflito e saúde ambiental é um aspecto que a Fiocruz aborda prioritariamente. Além disso, a produção da CPT é mais vasta do que a da Fiocruz nesse sentido, o que não as coloca em mesmo patamar de volume de conteúdo analisado.

Em termos de formato, o Mapa da Fiocruz possibilita uma maior interação entre o usuário e a ferramenta online, enquanto que para ter acesso aos Cadernos de Conflito é preciso fazer o download no site da CPT (ou acessá-los em formato impresso). As fichas com detalhes de cada situação estão acessíveis no próprio site em que está divulgado o Mapa; nos Cadernos, há apenas a síntese numérica, fruto de uma série de fichas das quais os agentes de campo da Pastoral extraem os dados e, posteriormente, arquiva.

Enquanto o discurso religioso aparece como uma proposta estruturante dos cadernos da CPT, a noção de saúde é apresentada como uma baliza para que se compreenda os efeitos práticos à saúde a partir dos conflitos. Nesse sentido, a recorrência com que a definição de saúde aparece, no Mapa, é desproporcional às citações que confirmam a dimensão teológica da publicação da CPT. Mas esta não é uma abordagem quantitativa, então, importa para nós tecer uma argumentação que aproxime saúde, teologia e conflitos a partir da análise dois conjuntos de publicações.

Se para a Fiocruz a questão da saúde aparece no sentido das implicações que os problemas acarretam aos sujeitos dos conflitos, a religião é um aspecto condutor do discurso que insere a igreja católica na luta e oferece uma justificativa divina para insistir no porquê os povos não devem ser sujeitados perante a Deus. Ao mesmo tempo, concilia esta abordagem com outras perspectivas, como por exemplo, a científica (basta ver nas seções de introdução dos Cadernos).

A compreensão de conflito, por sua vez, anterior às motivações específicas das instituições em suas frentes de trabalho, é o elo de ligação entre ambas. Em nosso entendimento, através desses argumentos relacionados à religião e à saúde, 
associados a outros saberes circundantes, a CPT e Fiocruz, através de seus mapeamentos, produzem uma narrativa que traz à tona os conflitos socioambientais no Brasil. Esta narrativa utilizaria credenciais específicas, baseada em fortes argumentos formais.

Os conflitos socioambientais, enquanto fenômeno heterogêneo da nossa agenda contemporânea, conclama saberes plurais para sua apreensão, motivação e desfecho. Não se trata, nesse artigo, de nivelar saberes, já que, a seu modo, ambas as publicações cumprem função primordial que é tornar público o problema e apontar criticamente suas raízes e possibilidades de evita-los. Deus e uma noção de saúde tem a ver com os conflitos socioambientais no Brasil tanto na medida em que os conflitos pertencem ao tecido social em que se costuram, numa perspectiva de confluência de saberes, inclusive, formas de conhecimentos tradicionais - não formais e não canônicas - e pouco admitidos em sua forma autóctone nos referidos materiais analisados.

\section{REFERÊNCIAS}

BALDUINO, Dom Tomás. Em meio à paixão e à esperança. In: Conflitos no Campo Brasil: 2003. AFONSO, José Batista Gonçalves; CANUTO, Antonio; LUZ, Regina Cassia Silva Luz. Goiânia: CPT, 2004. ISSN 1676-661.

BISPOS, Conferência Nacional dos. Igreja e problemas da terra. Itaici: CNBB, 1980. 20 p. Disponível em: https://pstrindade.files.wordpress.com/2015/01/cnbb-doc-17igreja-e-problemas-da-terra.pdf. Acesso em: 25 nov. 2018.

BOECKER, Hans Jochen. Os Pobres Possuirão a Terra: Pronunciamento de bispos e pastores sinodais sobre a terra. Cidade: São Paulo. Editora Sinodal, 2004.

BOECKER, Hans Jochen. Conflitos no Campo Brasil: 2011. Goiânia: CPT, 2012.

BOECKER, Hans Jochen.. Conflitos no Campo Brasil: 2013. Goiânia: CPT, 2014.

CANUTO, Antonio; COSTA, Edmundo Rodrigues Costa; LUZ, Cássia Regina da Silva. Conflitos no Campo Brasil: 2014. Goiânia: CPT, 2015. 
CORTES, Pe. José Cortes. O Baixo Amazonas entre conflitos. In: Conflitos no Campo Brasil 2010/ CPT; organização e seleção: Antônio Canuto, Cássia Regina da Silva Luz, Isolete Wichinieski. Goiânia: CPT, 2011.

DIAS, Edson Matias. Ecologia, Mundialização e Espiritualidade. Caminhos, Goiânia, v. 8, n. 2, p.171-206, dez. 2010. Disponível em:

http://seer.pucgoias.edu.br/index.php/caminhos/article/view/1344/90. Acesso em: 25 nov. 2018.

FAUSTINO, Cristiane et. al. O Mapa como Espaço de Cidadania: reflexões e continuidades. In: Injustiça ambiental e saúde no Brasil: o Mapa de conflitos. PORTO, Marcelo Firpo; PACHECO, Tania; LEOY, Jean Pierre (org.). Rio de Janeiro: Editora FIOCRUZ, 2013.

FERREIRA, Lúcia da Costa. A Equação Dinâmica entre Conflitos Sociais, Recursos Naturais e Desastres Ambientais: O Estado da Arte e uma Proposta Teórica. In: VI Encontro Nacional da Anppas. Belém, 2012.

FREITAS, Carlos Machado de. A produção científica sobre o ambiente na saúde coletiva. Cad. Saúde Pública [online]. 2005, vol.21, n.3, pp.679-701. Disponível em: http://www.scielo.br/pdf/csp/v21n3/03.pdf. Acesso em: 25 nov. 2018.

GALLAZZI, Anna Maria Rizzante. Conflitos, violência: um olhar pastoral. In: Conflitos no Campo - Brasil 2013. Coordenação: Antônio Canuto, Cássia Regina da Silva Luz, Flávio Lazzarin. Goiânia: CPT Nacional, Brasil, 2014.

GALTUNG, Johan. Peace By Peaceful Means: Peace and Conflict, Development and Civilization. Oslo: Sage Publications, 1996. Disponível em: https://goo.gl/wsUT52. Acesso em: 19 de mar. de 2017.

HAYES, Bernadette C.; MARANGUDAKIS, Manussos. Religion and Environmental Issues within Anglo-American Democracies. Review Of Religious Research, London, v. 42, n. 2, p.159-174, dez. 2000. Disponível em: https://www.jstor.org/stable/3512527. Acesso em: 25 nov. 2018.

LEROY, Joaquim Pierre; PORTO, Marcelo Firpo; PACHECO, Tania (org.). Mapa de Conflitos Envolvendo Injustiça Ambiental e Saúde no Brasil. 2010. Disponível em: https://goo.gl/T5BT1d. Acesso em: 19 de mar. 2017.

PAIM, Jairnilson Silva. Desafios para a Saúde Coletiva no Século XXI. Salvador: Edufba, 2006. 154 p. 
PEREIRA, Clevisson Junior. Geografia da Religião: Um olhar panorâmico. 2013. RA'E GA, Curitiba, v 27, 2013. Disponível em: https://revistas.ufpr.br/raega/article/download/30414/19689. Acesso em: 30 dez. 2018.

PEREIRA, Pilato. Justiça e paz com a criação: a ecologia em interação com justiça e paz na experiência prática e reflexiva do Conselho Mundial de Igrejas. Dissertação. Faculdade de Teologia, PUCRS, Porto Alegre, 2012. Disponível em: http://repositorio.pucrs.br/dspace/handle/10923/5256. Acesso em: 30 dez. 2018.

PORTO, Marcelo Firpo de Souza; ROCHA, Diogo Ferreira da; FINAMORE, Renan. Saúde coletiva, território e conflitos ambientais: bases para um enfoque socioambiental crítico. Ciênc. saúde coletiva, Rio de Janeiro, v. 19, n. 10, Oct. 2014. Disponível em: http://www.scielo.br/pdf/csc/v19n10/1413-8123-csc-19-10-4071.pdf. Acesso em: 25 nov. 2018.

REIMER, Haroldo. Crise Ecológica: Uma Visita de Deus. Estudos Teológicos, São Leopoldo, v. 3, n. 32, p.226-239, 1992. Disponível em: http://ism.edu.br/periodicos/index.php/estudos_teologicos/article/download/975/944. Acesso em: 25 nov. 2018. 